\title{
Unique Roles of Mothering and Fathering in Child Anxiety; Moderation by Child's Age and Gender
}

\author{
Marjolein Verhoeven • Susan M. Bögels • \\ Corine C. van der Bruggen
}

Published online: 20 April 2011

(C) The Author(s) 2011. This article is published with open access at Springerlink.com

\begin{abstract}
We examined the associations between the parenting dimensions autonomy granting, over control, and rejection and children's anxiety, in relation to parent and child gender and child age. Elementary school-aged children $\left(n=179, M_{\text {age }}=10.27, S D=1.30\right)$, adolescents $\left(n=127, M_{\text {age }}=15.02, S D=1.54\right)$ and both their parents completed questionnaires on parenting and children's anxiety. Parenting was more strongly related to child anxiety in elementary school children than in adolescents. Maternal over control was uniquely related to elementary school-aged children's anxiety whereas paternal over control was more important during adolescence. Opposite to our expectations, we found higher levels of parental autonomy granting to be related to higher levels of anxiety for younger elementary school-aged children (age $<10$ ). For adolescents, the association between paternal over control and anxiety was stronger for older adolescents (age $>15$ ), with higher levels of over control related to higher levels of anxiety. For both elementary school-aged children and adolescents, the associations between parenting and child anxiety did not differ as a function of the child's gender. If we are to understand the associations between parenting and children's anxiety, it is important to distinguish parental autonomy granting from parental over
\end{abstract}

M. Verhoeven ( $\square)$

Research Centre Psychosocial Development in Context, Utrecht University, P.O. Box 80144, 3508 TC Utrecht, the Netherlands e-mail: J.C.T.Verhoeven@uu.nl

S. M. Bögels · C. C. van der Bruggen Child Development and Education, University of Amsterdam, Amsterdam, the Netherlands control and to consider the role of parent gender and the age of the child.

Keywords Anxiety - Mothering · Fathering ·

Adolescence $\cdot$ Childhood

\section{Introduction}

Feelings of anxiety are common and normal during childhood and adolescence (e.g. Ollendick et al. 2002), but for more than $20 \%$ of normal schoolchildren these feelings reflect significant underlying anxiety problems and approximately $5-17 \%$ of children and adolescents have an anxiety disorder (e.g., Costello and Angold 1995). This underlines the importance of understanding the correlates of anxiety symptoms during childhood. A growing body of studies has documented a relationship between parental behaviors and children's anxiety symptoms (i.e., Ballash et al. 2006; Wood et al. 2003). However, the moderate magnitude of these associations (for meta-analytic reviews, see McLeod et al. 2007; Van der Bruggen et al. 2008) indicates that there is considerable variability in the levels of anxiety experienced by children receiving similar levels of parenting. Identifying precise conditions that attenuate or amplify the associations between parenting and child anxiety is therefore an important next step. Parent and child gender, as well as child age, have been postulated as potential sources of variability in associations between parenting and anxiety (Bögels and Perotti 2010; Bögels and Phares 2008; Van der Bruggen et al. 2008). With this study we examined (a) whether the associations between parenting and child anxiety are similar for mother and fathers, and (b) whether the child's gender and age moderate these associations. 
Two broad parenting dimensions that have been identified to play an important role in children's anxiety are control and rejection (Hudson and Rapee 2001; McLeod et al. 2007; Wood et al. 2003). Parental over control (i.e., excessive parental regulation of children's activities and routines, encouragement of children's dependence on parents, and instructions to children how to think and feel (McLeod et al. 2007)), as opposite to parental autonomy granting, is thought to enhance child anxiety by increasing the child's perception of threat, reducing the child's perceived control over threat, and withdrawing the child from opportunities to explore the environment and develop new skills to cope with unexpected events (Hudson and Rapee 2001; Rapee 1997). High levels of parental rejection (i.e., parental hostility, indifference, noninvolvement, and criticism), as opposite to parental acceptance, are thought to increase child anxiety by attacking the child's self esteem and integrity and therewith increase the child's sensitivity to anxiety (e.g., Gottman et al. 1997; Wood et al. 2003). Although both parental control and parental rejection have been found associated with anxiety symptoms in children and adolescents, two recent meta-analyses revealed that parental controlling behaviors play the most important role in child anxiety (McLeod et al. 2007).

In previous studies, parental over control and autonomy granting on the one hand and parental rejection and acceptance on the other hand have often been viewed -and assessed- as opposite ends of two broad dimensions of parenting. It has recently been challenged whether such a conceptualization is appropriate for these two dimensions of parenting. Firstly, parental over control and autonomy granting reflect two different constructs of parenting that both comprise different parental behaviors. Items to measure parental autonomy granting often refer to parental stimulation of being an independent person, whereas items measuring parental over control refer to the extent to which children are allowed to undertake certain activities by themselves. Likewise, items to assess parental acceptance differ from items assessing parental rejection, as they ask for indicators of warmth and support and not for indicators of hostility and punishment (Markus et al. 2003; Sentse et al. 2010). Combining these items into one construct of parenting makes it difficult to interpret findings. There is also statistical evidence that items assessing parental psychological control (i.e., invalidating feelings, guilt induction) and autonomy granting are best represented by two different constructs, rather than one broad parenting dimension (Silk et al. 2003). A study by Sentse et al. (2010) showed that the correlation between parental rejection and acceptance was moderate and should be treated as separate constructs. Secondly, parental over control, autonomy granting, rejection and acceptance might be of different importance for child anxiety. That is, the risk effects of negative parenting (e.g., over control and rejection) may be stronger than the positive effects of positive parenting (e.g., autonomy granting and acceptance). Indeed, McLeod et al. (2007) established stronger associations with children's anxiety levels for autonomy granting compared to excessive over involvement. They also found that parental warmth (e.g., acceptance) played only a small role in explaining children's levels of anxiety, whereas at the same time parental rejection (e.g., aversiveness and withdrawal) was more strongly related to children's anxiety. These findings reinforce the need to disaggregate dimensions of parenting into more specific components of parenting as they may represent unique correlates of childhood anxiety. We therefore decided to focus on the dimensions of parental over control, autonomy granting, rejection and acceptance to examine the role of these specific parenting behaviors in child anxiety. Knowledge regarding the importance of specific parenting behaviors will help us to develop more targeted interventions.

Besides the importance of gaining a better understanding of how specific parenting behaviors are associated with child anxiety, it is also important to know if and how these associations are influenced by other factors. Parent and child gender and the child's developmental stage have been mentioned as possible moderators of the association between parenting and anxiety (e.g., Bögels and Phares 2008). Regarding parental gender, there seems to be the assumption that mothers are more important than fathers in child development, based on the fact that mothers spend more time with their children (Parke 2002). This assumption, however, has not often been tested as fathers have been largely ignored in studies on associations between parenting and child anxiety (Bögels and Perotti 2010; Bögels and Phares 2008). Moreover, data from the few studies that did involve fathers cast doubt on the validity of the assumption that mothers are more important than fathers when it comes to child anxiety. Barrett et al. (2005) as well as Bögels et al. (2008) found that both mothers and fathers of clinically anxious children showed higher rates of controlling behaviors than mothers and fathers of children in a normal control-group, suggesting that the associations between parenting and child anxiety are similar for mothers and fathers. In the same vein, Greco and Morris (2002) showed that during a challenging task, observers rated fathers of socially anxious children as more controlling than fathers of non-anxious children. However no mothers were included in this study. A meta-analysis by Van der Bruggen et al. (2008) also provides tentative support for the idea that paternal rearing is important in child anxiety. That is, the association between parental control and child anxiety was stronger in studies that did include father ( $n=5, d=.84)$ than in studies including mothers only ( $n=18, d=.50)$, although it should be 
mentioned that this difference in effect size was not significant. In contrast, Hudson and Rapee (2002) observed that mothers of clinically anxious children (aged 6-17) were more highly involved in a complex puzzle-task than mothers of non-anxious children, whereas this difference was not found for fathers. Thus, there is empirical evidence that parental gender is a possible moderator of the association between parenting and child anxiety, but this evidence is scarce and inconclusive.

Not only parental gender has been conceptualized as a potential source of variability in associations between parenting and children's anxiety; also the child's gender and age have been mentioned as possible moderators. Regarding the child's age, it might be that parental rearing influences become smaller when the child gets older, as older children spend much less time with their families (Larson and Richards 1991). In line with this, Scott et al. (1991) found only a small effect of parental nurturance (i.e., acceptance) in adolescents, whereas for elementary school-aged children Siqueland et al. (1996) established a large effect of maternal acceptance on children's levels of anxiety. However, McLeod et al. (2007) did not find a moderating effect of the child's age in their meta-analysis, in which study samples ranged between mean ages of 2-18 years. Unfortunately, there are not many studies that included longitudinal data or data from different cohorts. As a result, the hypothesis regarding the moderating role of the child's age has not often been tested directly. One exception is a study by Hudson and Rapee (2001) in which the relationship between children's anxiety and general maternal involvement was examined in 95 children aged between 7 and 15 years. They found that although in general maternal control (i.e., intrusive involvement) decreased with age, the significant differences between maternal control levels in anxious versus non-clinical children did not vary across age. In other words, the magnitude of association between parenting and child anxiety did not change with age.

The child's gender has also been postulated as a possible moderator of the association between parenting and child anxiety, and there is indeed some evidence to support this. For example, in their observational study Krohne and Hock (1991) found that mothers of highly anxious girls between 10 and 13-years were more likely to intrude upon the child's problem-solving behaviors than mothers of nonanxious girls. This relationship was not found for boys. In their meta-analysis, Van der Bruggen et al. (2008) also found stronger effects between observed parental control and anxiety for girls than for boys. The meta-analysis performed by McLeod et al. (2007) on the other hand, found no evidence for a moderating role of child gender. These previously mentioned studies were mainly concerned with maternal behavior, whereas it has been argued that the child's gender may be especially important in the potentially different roles of mothers and fathers. For example, parental influence may be stronger in same-sex parent-child dyads (Bögels and Phares 2008). However, the only study that we are aware of that directly tested this hypothesis found that in general, observed parental control was more strongly related with child anxiety in boys than girls and that this was the case for both maternal and paternal behavior (Van der Bruggen et al. 2010).

One of the most recent theories on how the associations between parenting and child anxiety are influenced by parental gender and child age and gender, is the theoretical model developed by Bögels and Phares (2008). According to this model, mothers and fathers uniquely contribute to their child's levels of anxiety and the extent of these contributions depends on the developmental phase and gender of the child. This model states that fathers may be particularly influential during infancy and again become more important when children grow older, especially during adolescence. For more positive developmental outcomes regarding anxiety levels, children need to have a close, interpersonal relationship with their mother and need their father to stimulate entry to the larger social world, risk taking and independence during middle childhood. When children reach adolescence, it is important that fathers grant their children more autonomy while staying close at the same time. For mothers it becomes important to "let go" (Bögels and Phares 2008). Translating this to the dimensions of parental control and rejection, this model anticipates that during middle childhood, maternal acceptance and rejection and paternal autonomy granting and over control are the most important correlates of children's anxiety levels. When children reach adolescence, paternal acceptance and rejection and both maternal and paternal autonomy granting and over control become important.

To summarize, we examined whether four parenting behaviors (autonomy granting, over control, acceptance, and rejection) are related to anxiety levels in children and adolescents and whether these associations are depended of parental gender and child age and gender. Based on results of previous studies (McLeod et al. 2007) and the theoretical model recently developed by Bögels and Phares (2008), we expected to find that parental controlling behaviors (i.e., autonomy granting and over control) will be more strongly related to child anxiety than parental acceptance and rejection. We hypothesized that maternal behavior is more strongly related to child anxiety during middle childhood than paternal behavior, whereas for the adolescent group we expected the reverse. For both middle childhood and adolescence, we anticipate the associations between parenting and child anxiety to be stronger for girls than for boys. 


\section{Method}

Participants

Elementary school-aged children (8-12 years) and adolescents (13-18 years) and their parents were recruited from Dutch schools (i.e., elementary schools, secondary schools and intermediate vocational education schools) in the South and North of Holland. Approximately 650 children received a letter for themselves and their parents with the request to participate in a study on the relationship between parenting and anxiety. Active consent was obtained from $585(91 \%)$ parents and students prior to survey administration. Since we were interested in the roles of both mothers and fathers only children who participated with both their mother and father were included in this study, reducing the sample to 306 families: 179 families with a child aged $8-12$ years $(M=10.27, S D=1.30)$ and 127 families with an adolescent aged 13-18 years ( $M=15.02, S D=1.54)$. Of these 306 families, $55 \%$ of the mothers and $61 \%$ of the fathers completed tertiary education. The majority (97.4-97.8\%) of the participating mothers and fathers were the biological parent of the child and approximately $93.5 \%$ of the mothers and fathers were married. Most families were Caucasian (99\%).

\section{Instruments}

\section{Child Anxiety}

Children and both parents completed the SCARED-71. In 1999, Muris, Merckelbach, Schmidt and Mayer alternated the original 38-item SCARED (Birmaher et al. 1997) into a 66-item questionnaire, the SCARED-R, which taps symptoms of all DSM IV defined anxiety disorders (American Psychiatric Association 1994). The SCARED-R is a reliable and valid questionnaire, with a good internal consistency of the total score in both nonclinical (range between .91 and .95) and clinical samples (ranges between .86 and .94; Muris et al. 2004; Muris et al. 1999a; Muris and Steerneman 2001). The test-retest reliability and concurrent validity are both satisfactory (Muris et al. 1998; Muris et al. 1999b). Bögels and Van Melick (2004) developed the SCARED-71 by expanding the SCARED-R with 5 social phobia items. The SCARED-71 shows high levels of internal consistency and has been found to be a valuable screening tool to detect clinically significant anxiety problems in children (8-12 years) and adolescents (13-18 years; Bodden et al. 2009).

The SCARED-71 lists 71 symptoms of anxiety on which the child and both parents have to indicate how frequently the child experiences these symptoms on a 3-point Likert scale $(0=$ never, $1=$ sometimes, and $2=$ often $)$. Internal consistency were $\alpha=.95$ for child self report, $\alpha=.96$ for maternal report and $\alpha=.95$ for paternal report. Correlations between maternal, paternal, and child report were all significant at $p<.001$ level with a mean correlation of $r=.56$, indicating there was moderate agreement between informants. It was therefore decided to combine the three reports.

\section{Rearing Dimensions}

The child and both parents reported about parenting behavior. The Rearing Behaviour Questionnaire (RBQ, Bögels and Van Melick 2004) is based on 23 items of the Mother-Father-Peer Inventory (MFP) (Epstein, Unpublished manuscript), and 10 items of the Child Report of Parental Behavior Inventory (CRPBI) (Schaefer 1965), all rated on a 4-point scale (from $1=$ not true at all to $4=$ very true). Regarding the items based on the MFP, seven items measured autonomy granting ("...encouraged me to make my own decisions"), six items measured over control ("...is overprotective"), five items measured acceptance ("...likes spending time with me"), and five items concerned rejection ("...doesn't like hanging around with me"). The ten items of the CRPBI measured over control, referring to parental attempts to exercise control over the child's psychological world ("...likes to control everything that I do").

In order to examine whether autonomy granting, over control, acceptance and rejection are distinct subdimensions of parenting rather than opposite ends of a continuum, we followed the procedure used by Silk et al. (2003). We provided six experts in the field of parenting, blind to the hypotheses of the study, with the definitions of the four parenting constructs and asked them to sort the 33 items into the four constructs. Agreement among raters was high (kappa $=.82$, ranging from .71 to .92). Five items were dropped because the raters could not assign them to one of the four constructs (i.e. "My mother/father has the feeling that (s)he has to fight for me when I have a fight with a teacher or a friend", "My mother/father forbids me to do things other children are allowed to do", "My mother/ father tells me about all the things (s)he did for me", "My mother/father only sticks to the rules if it is in her/his convenience", "My mother/father doesn't want me to grow up"). The other 28 items were then subjected to confirmatory factor analyses using LISREL 8.80 (Jöreskog and Sörbom 2007). Separate models were tested for child reports on mothering, child reports on fathering, maternal self-reports and paternal self-reports.

First, a two-factor model was tested in which the items of autonomy granting and over control loaded on one factor and the items of acceptance and rejection loaded on a second factor. Next, a four-factor model was examined, with 
separate factors for the four parenting constructs. As indicated in Table 1, the fit-indices for the two-factor models were not acceptable (for example, RMSEA ranged from .08 to .13 , CFI ranged from .81 to .83 ). The four-factor models, on the other hand, fit the data well, with all Fit-indices in acceptable ranges. In addition, a chi-square difference test showed that the four-factor solution fitted the data better than the two-factor solution. Also, the AIC-scores of the fourfactor solution are substantially lower for both child reports and parental self reports. Correlations between the factors of autonomy granting and overprotection ranged from -.28 to -.37 for the child and parental reports respectively. For the factors of acceptance and rejection, these correlations ranged from .01 to -.21 . These low to moderate correlations further strengthen our idea that the four factors represent distinct constructs of parenting.

Each item loaded significantly on the appropriate latent construct (Table 2). Exceptions to this were the factor loadings of the items that measured maternal acceptance; for maternal self-reports these items did not reach significance. In addition, the internal reliability of maternal and paternal self-reported acceptance was not sufficient, $\alpha_{\text {Mother }}=.39, \alpha_{\text {Father }}=.53$ and this parenting construct was therefore dropped from further analyses. Internal consistency for the other three parenting constructs, however, were acceptable, ranging from .65 to .78 (mean $\alpha=.73$ ).

\section{Results}

There was a relatively low to moderate agreement between parents and children regarding the reports of the three parenting constructs, with correlations between child reports and parental self-reports ranging from $r=.13$ to $r=.22$ (mean $r=.18$ ). All following analyses were conducted separately for child reported parenting, parent's self reported parenting and the combined measures of child and parental reported parenting. These analyses revealed similar results. As the reliability and validity of rearing questionnaires improves when increasing the number of informants (Bögels and Van Melick 2004), we only present the results regarding the combined reports of children and parents.

\section{Preliminary Analyses}

For elementary school-aged children (hereafter referred to as 'children'), age was negatively related to anxiety, $r=$ $-.20, p<.01$, so that older children had lower levels of anxiety than younger children. The child's age was also related to maternal behavior, with mothers displaying higher levels of autonomy granting, $r=.17, p<.05$, and lower levels of over control, $r=-.15, p<.05$, when their child was older. Paternal parenting, however, was not related to the child's age. The child's gender was not related to children's anxiety levels or to parenting behavior. Parent gender, on the other hand, was related to differences in parenting behavior. Paired $t$ tests revealed mothers were higher on over control, $M=1.93, S D=.41$, than fathers, $M=1.81, S D=.38, \quad t \quad(178)=4.42$, $p<.001$. Mothers and fathers did not differ in the levels of autonomy granting, $t(178)=-.48$, n.s., or rejection, $t(178)=-1.36$, n.s.

For adolescents, neither age nor gender was associated with levels of anxiety. In addition, adolescents' age was not related to parenting. Mothers and fathers showed similar levels of over control, $t(126)=1.28, n . s$., autonomy granting, $t(126)=-.10$, n.s., and rejection, $t(126)=-1.36$, n.s.

Table 1 Fit indices for two-factor and four-factor measurement models

\begin{tabular}{|c|c|c|c|c|c|c|c|c|c|}
\hline & $\chi^{2}$ & $d f$ & RMSEA & CFI & NNFI & AIC & $\Delta \chi^{2}$ & $\Delta d f$ & $p$ \\
\hline \multicolumn{10}{|l|}{ Child reports } \\
\hline \multicolumn{10}{|l|}{ Mother } \\
\hline Two factors & 1057.92 & 348 & .10 & .81 & .80 & 1620.93 & \multirow[t]{2}{*}{477.80} & 5 & \multirow[t]{2}{*}{$<.001$} \\
\hline Four factors & 580.12 & 343 & .05 & .94 & .93 & 717.16 & & & \\
\hline \multicolumn{10}{|l|}{ Father } \\
\hline Two factors & 2012.13 & 349 & .13 & .81 & .80 & 2126.13 & \multirow[t]{2}{*}{1132.43} & 5 & \multirow[t]{2}{*}{$<.001$} \\
\hline Four factors & 755.70 & 344 & .06 & .92 & .91 & 879.70 & & & \\
\hline \multicolumn{10}{|l|}{ Self reports } \\
\hline \multicolumn{10}{|l|}{ Mother } \\
\hline Two factors & 1014.62 & 345 & .08 & .83 & .82 & 1136.62 & 313.89 & 5 & $<.001$ \\
\hline Four factors & 700.73 & 340 & .06 & .93 & .92 & & & & \\
\hline \multicolumn{10}{|l|}{ Father } \\
\hline Two factors & 1041.57 & 342 & .08 & .83 & .82 & 1169.57 & 479.25 & 5 & $<.001$ \\
\hline Four factors & 562.32 & 337 & .05 & .92 & .91 & 700.32 & & & \\
\hline
\end{tabular}


Table 2 Standardized regression weights of child reports of mothering/fathering

\begin{tabular}{|c|c|c|c|c|c|c|c|c|c|}
\hline & & \multicolumn{4}{|c|}{ Child report } & \multicolumn{4}{|c|}{ Parental report } \\
\hline & & Acc & Rej & Aut & Overcon & Acc & Rej & Aut & Overcon \\
\hline 1. & $\begin{array}{l}\ldots \text { sometimes disapproves things that I do, but (s)he } \\
\text { never rejects me as a person }\end{array}$ & $.30 / .38$ & & & & $.11 / .21$ & & & \\
\hline 2. & ... likes spending time with me & $.39 / .58$ & & & & $.25 / .28$ & & & \\
\hline 3. & ... tries to make me feel better when I'm unhappy & $.51 / .67$ & & & & $.30 / .39$ & & & \\
\hline 4. & $\begin{array}{l}\text {... gives me the feeling that (s)he loves me just the way I am; } \\
\text { (s)he doesn't want to change the person I am }\end{array}$ & $.69 / .58$ & & & & $.30 / .41$ & & & \\
\hline 5. & I can depend on my mother/father if I really need his/her help & $.41 / .52$ & & & & $.15 / .16$ & & & \\
\hline 6. & $\ldots$ is not easily satisfied & & $.43 / .51$ & & & & $.25 / .44$ & & \\
\hline 7. & $\ldots$ is often quite tough with me & & $.51 / .54$ & & & & $.36 / .41$ & & \\
\hline 8. & ... doesn't like hanging around with me & & $.24 / .27$ & & & & $.14 / .06$ & & \\
\hline 9. & ... keeps trying to change who I am & & $.46 / .41$ & & & & $.35 / .36$ & & \\
\hline 10. & $\ldots$ is less friendly when we see things differently & & $.33 / .45$ & & & & $.27 / .35$ & & \\
\hline 11. & ... doesn't look at me when I've disappointed him/her & & $.24 / .29$ & & & & $.31 / .17$ & & \\
\hline 12. & $\ldots$ gives me the feeling that I'm a burden to him/her & & $.44 / .39$ & & & & $.21 / .11$ & & \\
\hline 13. & ... never spends much time with me & & $.35 / .37$ & & & & $.31 / .23$ & & \\
\hline 14. & $\begin{array}{l}\text { When I've hurt my mother's/father's feelings, (s)he } \\
\text { stops talking to me until I please her/him again }\end{array}$ & & $.36 / .28$ & & & & $.17 / .19$ & & \\
\hline 15. & ... encourages me to take my own decisions & & & $.67 / .82$ & & & & $.55 / .48$ & \\
\hline 16. & ... helps me to become an independent person & & & $.65 / .73$ & & & & $.46 / .46$ & \\
\hline 17. & $\ldots$ encourages me to do things by myself & & & $.58 / .64$ & & & & $.34 / .41$ & \\
\hline 18. & ... encourages me to do things my own way & & & $.59 / .69$ & & & & $.47 / .40$ & \\
\hline & ... supports me when I do new, exciting things & & & $.42 / .44$ & & & & $.27 / .38$ & \\
\hline 20. & ... lets me decide over my own money & & & $.35 / 36$ & & & & $.19 / .26$ & \\
\hline 21. & ... encourages me to give my own opinion & & & $.75 / .76$ & & & & $.43 / .44$ & \\
\hline 22. & $\ldots$ is overprotective & & & & $.35 / .46$ & & & & $.38 / .22$ \\
\hline 23. & ... keeps telling me how to behave & & & & $.56 / .55$ & & & & $.39 / .43$ \\
\hline & $\begin{array}{l}\text {... tells me that, if I really care about him/her, I wouldn't } \\
\text { do anything that worries him/her. }\end{array}$ & & & & $.46 / .42$ & & & & $.34 / .35$ \\
\hline 25. & ... likes to tell me what to do and how to behave all the time & & & & $.46 / .49$ & & & & $.47 / .38$ \\
\hline 26. & $\ldots$ is too worried that I will hurt myself or that I will become ill & & & & $.49 / .45$ & & & & $.37 / .33$ \\
\hline 27. & ... wants to do things for me that I can easily do myself & & & & $.43 / .43$ & & & & $.42 / .26$ \\
\hline 28. & ... wants to control everything that I do & & & & $.41 / .41$ & & & & $.45 / .38$ \\
\hline
\end{tabular}

All factor loadings are significant $(p<.001)$ with exception of the loadings for maternal self reported acceptance

Acc parental acceptance, Rej parental rejection, Aut parental autonomy granting, Overcon parental over control

Mothers of adolescent boys, $M=1.87, S D=.43$, scored higher on over control than mothers of adolescent girls, $M=1.71, S D=.41, t(119)=2.04, p<.05$. Paternal parenting was not related to the gender of the adolescent.

The finding that age is differently associated with anxiety and parenting in children than in adolescents reflects that these associations are not linear from middle childhood to adolescence. We therefore decided to conduct the following analyses separately for elementary school-aged children (8-12 years) and adolescents (13-18 years). The transition from elementary school to high school at age 12 demarcates an important developmental step in Dutch children in the transition to the external world. In general, high schools are characterized by much larger size and the children being much older (13-18) compared to elementary schools, the physical distance from home is much larger, children are being more challenged to perform, receive homework for the first time, and have to take responsibility for their school books themselves. Therefore, this appeared the best division into development/age groups.

\section{The Role of Parent Gender}

For children, high levels of maternal and paternal over control and rejection were found to be correlated with higher levels of child's anxiety (Table 3). Fisher-z tests 
showed that these associations were equally strong for mothers and fathers, $z_{\text {Over control }}(178)=-.76, p=.45$, $z_{\text {Rejection }}(178)=-.79, p=.43$. In the adolescent sample, paternal behavior, but not maternal behavior, was related to adolescent's levels of anxiety (Table 3). That is, paternal over control was significantly correlated with adolescent's anxiety $(r=.23, p<.05)$, whereas maternal over control was not $(r=-.01, n . s$.$) . However, the difference in$ strength of these associations between adolescent's anxiety and maternal and paternal over control was only marginal, Fisher- $z(126)=1.92, p=.06$. In addition, the association between adolescent's anxiety and parental rejection was statistically significant for fathers $(r=.19, p<.05)$, but not for mothers $(r=.10, n . s$.$) , but the difference$ in strength of these associations was not significant, Fisher- $z(126)=.27, p=.47$.

Regression analyses reported in Table 4, showed that the child's age and gender and maternal behavior explained $21 \%$ of the variance in children's anxiety level in elementary school aged children, $F(5,170)=8.43, p<.001$. Maternal behavior explained $15 \%$ of the variance, with higher levels of maternal over control being related to higher levels of anxiety, $\beta=.31, p<.001$. The model in which the contribution of paternal behavior was examined, explained $16 \%$ of the variance in child's anxiety, $F(5,170)=6.32$, $p<.001$. Paternal behavior explained $11 \%$ of the variance in anxiety, with paternal over control being related to more child anxiety, $\beta=.29, p<.001$. The regression model in which maternal and paternal parenting dimensions were entered simultaneously showed that maternal, but not paternal behavior, had a unique effect on children's anxiety levels, $\Delta R^{2}=.15, p<.001, F(8,170)=5.65, p<.001$ (Table 4). Maternal over control explained a significant portion of the variance in children's anxiety levels, $\beta=.24$, $p<.01$. Note that the effect of paternal over control, which was found to be significant in the father model, no longer reached significance. This indicates that paternal over control had no unique effect on children's anxiety levels once controlled for the effects of maternal parenting. Changing the order in which maternal and paternal behavior was entered in the regression analysis (with paternal behavior entered first) lead to the same conclusion. So, once controlled for paternal behavior, maternal over control still had a unique effect on children's levels of anxiety.

For adolescents, regression analyses showed that the adolescent's gender and age and maternal behavior did not explain a significant portion of the variance in anxiety, $3 \%$, $F(5,120)=.63, p=.68$ (Table 4$)$. The model that tested the effects of paternal behavior, on the other hand, explained $9 \%$ of the variance in adolescent's anxiety levels, $F(5,120)=2.21, p=.06$, with paternal behavior explaining $7 \%$ of the variance. None of the coefficients

Table 3 Correlations between children's and adolescents' anxiety and maternal and paternal behavior

\begin{tabular}{|c|c|c|c|c|c|c|c|c|}
\hline & 1. & 2. & 3. & 4. & 5. & 6. & $M$ & SD \\
\hline \multicolumn{9}{|l|}{ Children } \\
\hline 1. Anxiety & & & & & & & 25.43 & 15.17 \\
\hline \multicolumn{9}{|l|}{ Mothering } \\
\hline 2. Autonomy granting & .05 & & & & & & 2.79 & .41 \\
\hline 3. Over control & $.40 * * *$ & .00 & & & & & 1.93 & .41 \\
\hline 4. Rejection & $.26 * * *$ & $-.15^{*}$ & $.46^{* * *}$ & & & & 1.42 & .30 \\
\hline \multicolumn{9}{|l|}{ Fathering } \\
\hline 5. Autonomy granting & .02 & $.55^{* * *}$ & .09 & -.01 & & & 2.80 & .43 \\
\hline 6. Over control & $.33 * * *$ & -.06 & $.60 * * *$ & $.33 * * *$ & -.08 & & 1.81 & .38 \\
\hline 7. Rejection & $.18^{*}$ & -.06 & $.24 * *$ & $.43 * * *$ & $-.16^{*}$ & $.34 * * *$ & 1.45 & .31 \\
\hline \multicolumn{9}{|l|}{ Adolescents } \\
\hline 1. Anxiety & .10 & & & & & & 19.14 & 12.58 \\
\hline \multicolumn{9}{|l|}{ Mothering } \\
\hline 2. Autonomy granting & .03 & & & & & & 3.02 & .47 \\
\hline 3. Over control & -.01 & -.13 & & & & & 1.76 & .42 \\
\hline 4. Rejection & .10 & $-.39 * * *$ & $.28 * *$ & & & & 1.36 & .33 \\
\hline \multicolumn{9}{|l|}{ Fathering } \\
\hline 5. Autonomy granting & -.06 & $.51 * * *$ & $-.18^{*}$ & -.14 & & & 3.02 & .43 \\
\hline 6. Over control & $.23 *$ & .00 & $.45^{* * *}$ & $.20^{*}$ & -.10 & & 1.72 & .38 \\
\hline 7. Rejection & $.19 *$ & -.09 & $.34 * * *$ & $.40 * * *$ & $-.27 * *$ & $.48 * * *$ & 1.40 & .28 \\
\hline
\end{tabular}

$* p>.05, * * p<.01 ; * * * p<.001$ 
Table 4 Parenting as predictor of child and adolescent anxiety

\begin{tabular}{|c|c|c|c|c|c|c|c|c|c|c|c|c|}
\hline & \multicolumn{4}{|c|}{ Mother model } & \multicolumn{4}{|c|}{ Father model } & \multicolumn{4}{|c|}{ Mother/Father model } \\
\hline & \multicolumn{2}{|l|}{ Child } & \multicolumn{2}{|c|}{ Adolescence } & \multicolumn{2}{|l|}{ Child } & \multicolumn{2}{|c|}{ Adolescence } & \multicolumn{2}{|l|}{ Child } & \multicolumn{2}{|c|}{ Adolescence } \\
\hline & $\beta$ & $\Delta R^{2}$ & $\beta$ & $\Delta R^{2}$ & $\beta$ & $\Delta R^{2}$ & $\beta$ & $\Delta R^{2}$ & $\beta$ & $\Delta R^{2}$ & $\beta$ & $\Delta R^{2}$ \\
\hline Step 1 & & $.06 * *$ & & .02 & & & & & & $.06 * *$ & & .02 \\
\hline Gender & .12 & & .14 & & & & & & $.13^{\#}$ & & $.17^{\#}$ & \\
\hline Age & $-.15^{*}$ & & -.06 & & & & & & $-.15^{*}$ & & -.04 & \\
\hline Step 2 & & $.15^{* * *}$ & & .00 & & & & & & $.15^{* * *}$ & & .00 \\
\hline Maternal Aut & .08 & & .05 & & & & & & .09 & & .04 & \\
\hline Maternal Overcon & $.31 * * *$ & & .00 & & & & & & $.24 *$ & & -.13 & \\
\hline Maternal Rejec & .12 & & .07 & & & & & & .11 & & .02 & \\
\hline$R^{2}$ & & $.21 * * *$ & & .03 & & & & & & & & \\
\hline Step 1 & & & & & & $.06 * *$ & & .02 & & & & $.08^{*}$ \\
\hline Gender & & & & & .13 & & $.19^{*}$ & & - & & - & \\
\hline Age & & & & & $-.17 *$ & & -.04 & & - & & - & \\
\hline Step $2 / 3$ & & & & & & $.11 * * *$ & & $.07 *$ & & .01 & & \\
\hline Paternal Aut & & & & & .08 & & -.03 & & -.02 & & -.06 & \\
\hline Paternal Overcon & & & & & $.29 * * *$ & & $.18^{\#}$ & & .14 & & $.23 *$ & \\
\hline Paternal Rejec & & & & & .09 & & .11 & & .03 & & .12 & \\
\hline$R^{2}$ & & & & & & $.16^{* * * *}$ & $.07 *$ & $.09^{\#}$ & & $.22 * * *$ & & .10 \\
\hline
\end{tabular}

Maternal Aut maternal autonomy granting, Maternal Overcon maternal over control, Maternal Rejec maternal rejection, Paternal Aut paternal autonomy granting, Paternal Overcon paternal over control, Paternal Rejec paternal rejection

$\# p<.07 ; * p<.05, * * p<.01 ; * * * p<.001$

reached significance, but a trend was found for paternal over control, with higher levels of this paternal behavior being related to higher levels of adolescent's anxiety, $\beta=.18, p=.08$. The regression model in which maternal and paternal parenting dimensions were entered simultaneously (see Table 4) showed that paternal, but not maternal behavior, had a unique effect on the levels of child anxiety, although the model did not reach significance, $\Delta R^{2}=.08, p<.05, F(8,120)=1.58, p=.14$. Once controlled for the effect of maternal behavior, paternal over control contributed significantly to adolescents' levels of anxiety, $\beta=.23, p<.05$. A model in which paternal behavior was entered in the first step and maternal behavior in the second step, led to similar conclusions. So, once controlled for maternal behavior, paternal over control had a unique effect on adolescent's levels of anxiety.

The Moderating Role of Child's Age and Gender

In order to examine whether the gender and age of the child moderated the associations between parenting and children's anxiety, each interaction term (i.e., gender versus maternal over control, age versus maternal over control etc.) was tested in a separate hierarchical regression model.
All independent variables were standardized before computing interactive terms. In the first step, the two lower terms were entered. In the second step the interactive term was added to the model. Within each cohort (children and adolescents) age was treated as a continuous variable.

For children, it was found that the child's age moderated the association between child anxiety and maternal autonomy granting, $\beta=-.20, p<.01, F(3,178)=5.58, p<.01$, and paternal autonomy granting, $\beta=-.18, p<.05, F(3$, $178)=5.17, p<.01$. Median splits were performed on each independent variable to depict the interactive effects in Figs. 1 and 2. Figure 1 shows that higher (lower) maternal autonomy granting was positively associated with higher (lower) levels of child's anxiety when the age of the child is below the median ( $<10.0$ years of age), whereas when the child's age is above the median ( $>10.0$ years of age) this parenting dimension is negatively related to anxiety. Figure 2 shows that paternal autonomy granting was positively related, but weakly, associated with children's anxiety. When children are younger than 10 years of age, this association is slightly stronger, so that higher levels of autonomy granting were related to higher levels of children's anxiety. Taken together, these results suggest that for younger children $(<10.0$ years of age) both maternal and paternal autonomy granting are related to higher levels of anxiety. 


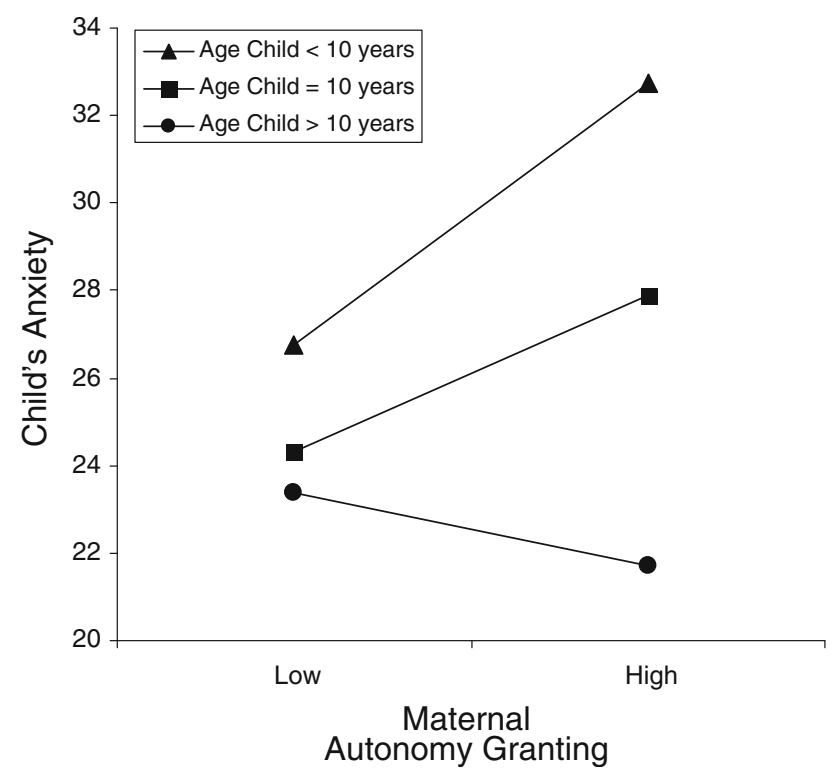

Fig. 1 Child's age as a moderator between maternal autonomy granting and children's levels of anxiety

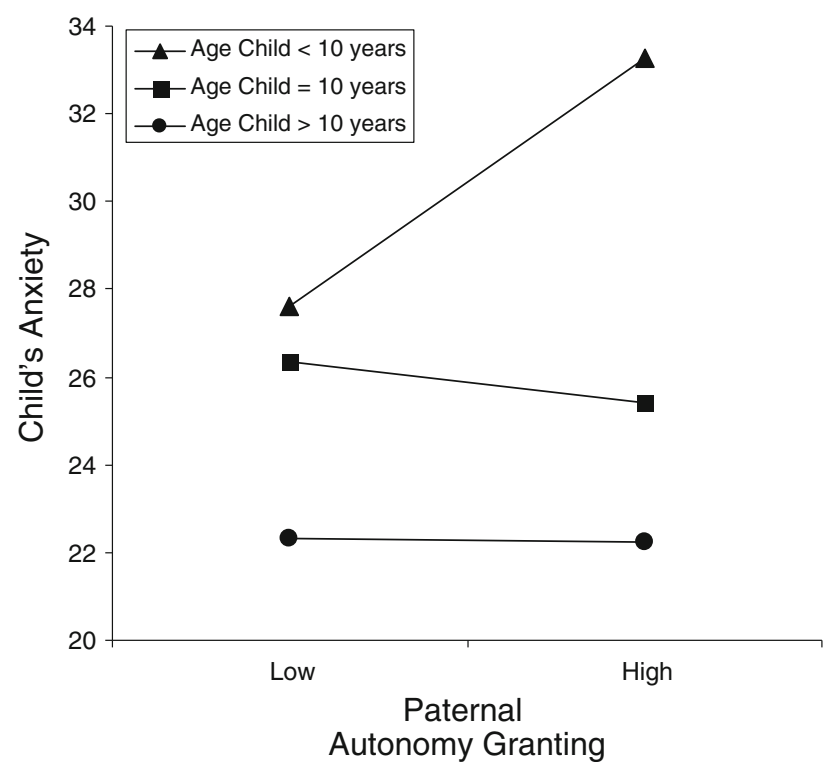

Fig. 2 Child's age as a moderator between paternal autonomy granting and children's levels of anxiety

For adolescents, a moderation effect of the child's age was found regarding the association between child anxiety and paternal over control, $\beta=.17, p=.05, F(3,126)=$ $3.62 p<05$. Figure 3 shows that in general, paternal over control was positively related to adolescents' anxiety levels. That is, when fathers show high (low) levels of over control, adolescents' show high (low) levels of anxiety. This link between paternal over control and adolescent's anxiety was stronger for older adolescents ( $>15$ years) than for younger adolescents.

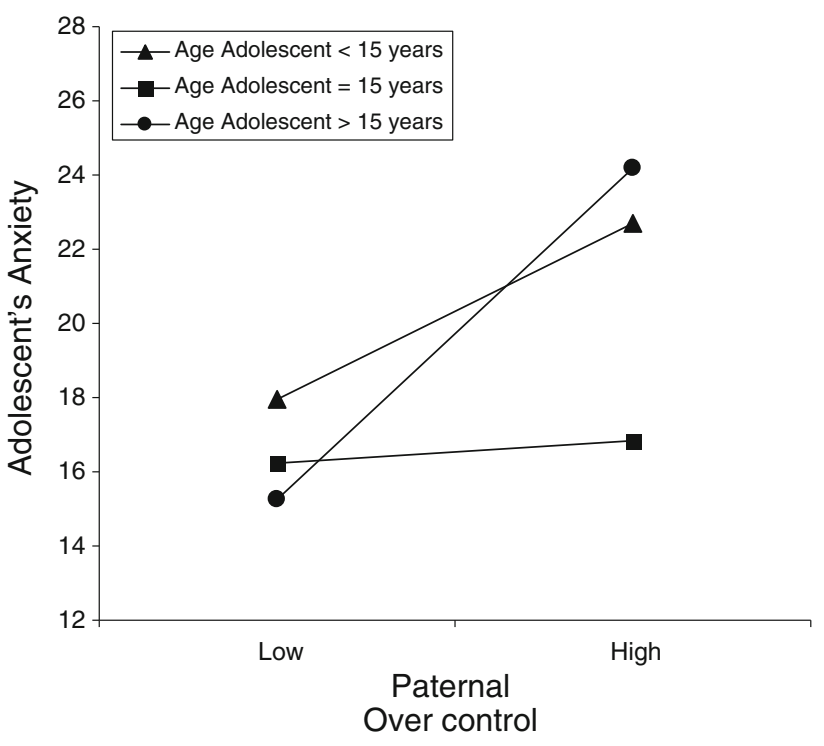

Fig. 3 Adolescent's age as a moderator between paternal over control and adolescent's levels of anxiety

The child's gender did not moderate the associations between parenting and anxiety, not for elementary school aged children nor for adolescents. That is, the associations between maternal and paternal behavior and child anxiety were similar for boys and girls.

\section{Discussion}

We examined the associations between parenting and child anxiety in elementary school-aged children (8-12 years) and adolescents (13-18 years) and whether these associations are different depending on parent and child gender and child age. In elementary school-aged children, both maternal and paternal levels of over control were associated with elevated levels of child anxiety, over and above the effects of parental autonomy granting and rejection. The finding that the effect of maternal over control was significant after controlling for levels of paternal parenting indicates that mothers play a unique role in anxiety in elementary schoolaged children. For both mothers and fathers the association between autonomy granting and children's anxiety was stronger in younger $(<10$ years) children than in older children. During adolescence, parenting played a less important role in child's anxiety. Maternal behavior was not associated with adolescent's anxiety and only a trend was found for the association between paternal over control and anxiety in this age group. The finding that paternal over control contributed to adolescent's anxiety after controlling for the effects of maternal behavior and paternal autonomy granting and rejection strengthens the idea that paternal over control plays a unique role in adolescent levels of anxiety. 
One of the aims of the current study was to examine whether parental over control and autonomy granting and parental rejection and acceptance represent distinct dimensions of parenting that are uniquely related to children's anxiety levels. In line with findings by Silk et al. (2003) and McLeod et al. (2007), a confirmatory factor analysis and low to moderate correlations between the parenting constructs showed that over control and autonomy granting and rejection and acceptance were best conceptualized as separate constructs. The finding that the dimensions over control versus autonomy granting were differentially related to children's levels of anxiety underline the importance of treating these parenting dimensions as separate constructs rather than as two ends of a continuum.

Unfortunately, the parenting construct of acceptance was not measured reliably by mothers' and fathers' self-reports. Especially in mothers' self reports, the factor loadings for the items that measured acceptance were weak. This is in line with a study by Adamson and Buehler (2007) that also found factor loadings of items measuring acceptance to be less strong for mothers than for fathers. Future studies should include a more reliable measure of parental acceptance, for example by including partner report in order to increase reliability and reduce possible social desirability answering tendencies (Bögels and Van Melick 2004), Research is needed to better understand how parents interpret self report measures and how self reported parenting correlates with observed parenting. The results regarding the role of the other three dimensions of parenting are discussed below.

For elementary school-aged children, we found that both maternal and paternal rejection and over control were associated with the child's levels of anxiety. As expected, higher levels of parental rejection and over control were linked to higher levels of children's anxiousness. This is in accordance with previous studies on the role of parental control in child anxiety (McLeod et al. 2007). For both mothers and fathers, the association between parental over control and anxiety was still significant after controlling for parental rejection. This suggests that parental over control is a more important contributor to child anxiety than parental rejection, as was also found by McLeod et al. (2007). As suggested by Rapee (1997), it might be that parental over control enhances child anxiety by increasing the child's perception of threat, reducing the child's perceived control over threat, and withdrawing the child from opportunities to develop skills to cope with unexpected events. The results of this study show that the levels of control of both mothers and fathers play an important role in child anxiety in elementary school-aged children (8-12 years).

Maternal and paternal autonomy granting were also associated with anxiety levels in elementary school-aged children, but in the opposite direction as hypothesized. These associations were moderated by the child's age. It was found that maternal and paternal autonomy granting was positively associated with anxiety in younger elementary school-aged children (age $<10$ ), but was unrelated to anxiety in older elementary school-aged children (age $>10$ ). In other words, for younger children, high levels of parental autonomy granting corresponded with higher levels of child anxiety. This is a remarkable finding, as it is generally found that autonomy granting is negatively linked to children's anxiety (McLeod, et al. 2007). Reasons that our findings differ from that of previous studies may have to do with our assessment of autonomy granting or our non-clinical sample. With respect to our assessment, very few studies have assessed autonomy granting separate from over control using questionnaire report. Also, we have studied a normal sample in which parents may adapt in a functional way to the developmental needs of their children, depending on children's anxiety levels.

Highly tentatively, the positive association between parental autonomy granting and child anxiety in younger children may indicate that too early autonomy granting can take the form of a lack of age-appropriate monitoring and supervision of the parent, resulting in elevated levels of child anxiety. Alternatively, our findings may suggest that in normal community samples parents of younger children with elevated anxiety levels try to help their offspring to overcome anxieties by stimulating their autonomy more strongly, whereas parents of younger children low on anxiety (e.g., children that may display risky, age inappropriate autonomous behavior) try to protect their children by refraining them from too early autonomy.

In addition to these two alternative explanations, note that our sample was restricted to families in which both mother and father completed questionnaires. As a result, families in which fathers are involved in childrearing may have been overrepresented. It is possible that families in which fathers are (highly) involved are different from families with low- or noninvolved fathers in ways that are related to parental autonomy granting, as autonomy granting is hypothesized to be a specific task for fathers (Bögels and Perotti 2010; Bögels and Phares 2008). Clearly, future studies are required to examine this interactive effect into more depth.

For adolescents, it was found that the associations between parenting and child anxiety were different for mothers and fathers. In contrast to our findings regarding school-aged children, maternal behavior did not significantly contribute to adolescents' levels of anxiety. Paternal over control, on the other hand, was associated with anxiety in adolescents, although the strength of this association was only marginal. The result that paternal over control 
contributed significantly to adolescent's anxiety above and beyond maternal behavior indicated that compared to mothers, fathers are more important for children's anxiety during this developmental phase. Additional analyses showed that the age of the adolescent moderated this association between paternal over control and adolescents' anxiety. That is, the link between paternal over control and adolescent's anxiety was strongest in older adolescents ( $>15$ years), so that especially older adolescents experienced higher levels of anxiety when their fathers were more controlling.

The findings that paternal over control was more important than maternal over control in adolescents' anxiety levels and that this association was stronger for older than for younger adolescents are in line with the model proposed by Bögels and Phares (2008). One of the developmental tasks of adolescents is to focus on the outside world and to become more independent from their parents. As according to this model the father represents the outside world, excessive paternal control, more than maternal control, might give the adolescent the signal that the outside world is a dangerous place, and that the adolescent cannot cope with it (Bögels and Phares 2008). If fathers do not accommodate the growing need of their adolescent children to become more independent by becoming less controlling, this could lead to feelings of anxiousness in adolescents. Further research is needed to examine to what extent maladaptive rearing styles (e.g., not becoming less controlling) are influential in the development and maintenance of anxiety symptoms during adolescence.

Although it was found that parent gender and child age played a significant role in the associations between parenting and child anxiety, this was not found for the child's gender. The relation between parenting and child anxiety did not differ for boys and girls. Previous results on the moderating role of child gender are contradictory. Consistent with our findings, McLeod et al. (2007) did not establish a child gender effect in their meta-analysis on the links between parenting and child anxiety. On the other hand, in their meta-analysis Van der Bruggen et al. (2008) found stronger parenting effects for girls than for boys. However, in a recent observational study in which parental control was measured while helping the child with a difficult Tangram puzzle, the same authors established stronger relations between parenting and child anxiety levels for boys than for girls (Van der Bruggen et al. 2010). These contradictory findings may be the result of including different samples (i.e., clinically anxious children versus community samples) or different measurement instruments (i.e., questionnaires versus observational measures, type of observational task). Future studies should examine the possible moderating role of child gender more structurally.
Limitations

When interpreting the findings of this study, it is important to keep in mind that this study concerned a community sample of mostly intact, two-parent families. These results may not generalize to other types of families. For example, we know from previous studies that children of divorced families are likely to experience higher levels of anxiety (Buchanan et al. 1991). Although it is important to gain knowledge on associations between parenting and variations in children's anxiety levels in 'normal' children, the results of the current study may also not apply to children with an anxiety disorder.

Another limitation is that the information on anxiety and parental behaviors was obtained by questionnaires and not through observations. Thus, one cannot draw conclusions regarding the associations between actual parenting behaviors and children's anxiety, but rather between perceived parenting and anxiety in children. Despite the weaknesses of self reports-like the bias towards socially desirable responses (O'Connor 2002)—we had good reasons to use questionnaires to obtain information on parenting. First, parents are in the unique position to report on a variety of behaviors across a wide range of situations, some of which are not readily visible in direct observations. Second, questionnaires can provide valuable and unique information regarding the parent's and children's subjective experiences. Additionally, a large body of research indicates that data on parenting obtained by questionnaires have predictive validity for children's developmental outcomes (Bögels and Brechman-Toussaint 2006).

Although the current study extends previous work on the associations between parenting and children's anxiety by examining this issue across two cohorts, the results are based on cross-sectional data and thus no conclusions can be drawn regarding the causality of the associations that were found. Experimental studies or studies using longitudinal data are necessary to examine the causality of the associations between parenting and children's anxiety.

Implications for Research and Practice

Nevertheless these limitations, the findings of the current study contribute to the existing knowledge of the associations between parenting and children's anxiety and have several implications for research and practice. First, different dimensions of parenting played different roles in children's anxiety. Second, mothers and fathers played different roles in anxiety in different cohorts: maternal over control contributed uniquely in elementary school-aged children, whereas paternal over control was more important in adolescents. Third, the child's age moderated the associations between parenting and children's anxiety levels. 
Future studies are required to replicate the findings of the current study and examine the underlying mechanisms with which parenting is associated with children's anxiety in more depth. For practitioners, these results indicate that intervention and prevention programs should not only be targeted at mothers but also at fathers, especially when raising an adolescent. Also, these programs should be concerned with a broad range of parenting behaviors and should take the child's age into consideration.

Open Access This article is distributed under the terms of the Creative Commons Attribution Noncommercial License which permits any noncommercial use, distribution, and reproduction in any medium, provided the original author(s) and source are credited.

\section{References}

Adamson, K., \& Buehler, C. (2007). Mothering versus fathering versus parenting: Measurement equivalence in parenting measures. Parenting, Science and Practice, 7, 271-303.

American Psychiatric Association. (1994). Diagnostic and statistical manual of mental disorders (4th ed.). Washington, DC: American Psychiatric Association.

Ballash, N., Leyfer, O., Buckley, A. F., \& Woodruff-Borden, J. (2006). Parental control in the etiology of anxiety. Clinical Child and Family Psychology Review, 9, 113-133.

Barrett, P. M., Fox, T., \& Farrell, L. J. (2005). Parent-child interactions with anxious children and with their siblings: An observational study. Behaviour Change, 22, 220-235.

Birmaher, B., Ketharpal, S., Brent, D., Cully, M., Balach, M., Kaufman, J., et al. (1997). The screen for child anxiety related emotional disorders (SCARED): Scale construction and psychometric characteristics. Journal of the American Academy of Child and Adolescent Psychiatry, 36, 545-553.

Bodden, D. H. M., Bögels, S. M., \& Muris, P. (2009). The diagnostic utility of the screen for child anxiety related emotional disorders71 (SCARED). Behaviour Research and Therapy, 47, 418-425.

Bögels, S. M., Bamelis, L., \& Van der Bruggen, C. O. (2008). Parental rearing as a function of parent's own, partner's, and child's anxiety status: Fathers make the difference. Cognition \& Emotion, 22, 522-538.

Bögels, S. M., \& Brechman-Toussaint, M. L. (2006). Family issues in child anxiety: Attachment, family functioning, parental rearing and beliefs. Clinical Psychology Review, 26, 834-856.

Bögels, S. M., \& Perotti, E. C. (2010). Does father know best? A formal model of the paternal influence on childhood social anxiety. Journal of Child and Family Studies, 20, 171-181. doi: 10.1007/s10826-010-9441-0.

Bögels, S. M., \& Phares, V. (2008). Fathers' role in the etiology, prevention and treatment of child anxiety: A review and new model. Clinical Psychology Review, 28, 539-558.

Bögels, S. M., \& Van Melick, M. (2004). The relationship between child-report, parent self-report, and partner report of perceived parental rearing behaviors and anxiety in children and parents. Personality and Individual Differences, 37, 1583-1596.

Buchanan, C. M., Maccoby, E. E., \& Dornbusch, S. M. (1991). Caught between parents: Adolescents' experience in divorced homes. Child Development, 62, 1008-1029.

Costello, E. J., \& Angold, A. (1995). Epidemiology. In J. S. March (Ed.), Anxiety disorders in children and adolescents (pp. 109-124). New York, NY: Guilford Press.
Gottman, J. M., Katz, L. F., \& Hooven, C. (1997). Meta-emotions: How families communicate emotionally. Malwah, NJ: Lawrence Erlbaum.

Greco, L. A., \& Morris, T. L. (2002). Paternal child-rearing style and child social anxiety: Investigation of child perceptions and actual father behavior'. Journal of Psychopathology and Behavioural Assessment, 24, 259-267.

Hudson, J. L., \& Rapee, R. M. (2001). Parent-child interactions and anxiety disorders: An observational study. Behaviour Research and Therapy, 39, 1411-1427.

Hudson, J. L., \& Rapee, R. M. (2002). Parent-child interactions in clinically anxious children and their siblings. Journal of Clinical Child \& Adolescent Psychology, 31, 548-555.

Jöreskog, K., \& Sörbom, D. (2007). LISREL (Version 8.80) [Computer Software]. Chicago, IL: Scientific Software International, Inc.

Krohne, H. W., \& Hock, M. (1991). Relationships between restrictive mother-child interactions and anxiety of the child. Anxiety Research, 4, 109-124.

Larson, R., \& Richards, M. H. (1991). Daily companionship in late childhood and early adolescence: Changing developmental contexts. Child Development, 62, 284-300.

Markus, M. T., Lindhout, I. E., Boer, F., Hoogendijk, T. H. G., \& Arrindell, W. A. (2003). Factors of perceived parental rearing styles: The EMBU-C examined in a sample of Dutch primary school children. Personality and Individual Differences, 34, 503-519.

McLeod, B. D., Wood, J. J., \& Weisz, J. R. (2007). Examining the association between parenting and childhood anxiety: A metaanalysis. Clinical Psychology Review, 27, 155-172.

Muris, P., Dreessen, L., Bögels, S. M., Weckx, M., \& Van Melick, M. (2004). A questionnaire for screening a broad range of DSMdefined anxiety disorder symptoms in clinically referred children and adolescents. Journal of Child Psychology and Psychiatry, $44,1-8$.

Muris, P., Merckelbach, H., Mayer, B., Van Brakel, A., Thissen, S., Mouleart, V., et al. (1998). The screen for child anxiety related emotional disorders and traditional childhood anxiety measures. Journal of Behaviour Therapy and Experimental Psychiatry, 29, 327-339.

Muris, P., Merckelbach, H., Schmidt, H., \& Mayer, B. (1999a). The revised version of the screen for child anxiety related emotional disorders (SCARED-R): Factor structure in normal children. Personality and Individual Differences, 26, 99-112.

Muris, P., Merkelbach, H., Van Brakel, A., \& Mayer, B. (1999b). The screen for child anxiety related emotional disorders (SCARED): Further evidence for its reliability and validity. Anxiety Stress and Coping, 12, 411-425.

Muris, P., \& Steerneman, P. (2001). The revised version of the screen for child anxiety related emotional disorders (SCARED-R): First evidence for its reliability and validity in a clinical sample. British Journal of Clinical Psychology, 40, 35-44.

O'Connor, T. G. (2002). Annotation: The 'effects' of parenting reconsidered: findings, challenges, and applications. Journal of Child Psychology and Psychiatry and Allied Disciplines, 43, 555-572.

Ollendick, T. H., King, N. J., \& Muris, P. (2002). Fears and phobias in children: Phenomenology, epidemiology, and aetiology. Child and Adolescence Mental Health, 7, 98-106.

Parke, R. D. (2002). Fathers and families. In M. H. Bornstein (Ed.), Handbook of parenting: Vol. 1. Children and parenting (pp. 27-73). Mahwah, NJ: Lawrence Erlbaum Associates.

Rapee, R. M. (1997). Potential role of childrearing practices in the development of anxiety and depression. Clinical Psychology Review, 17, 47-67. 
Schaefer, E. S. (1965). Children's report of parental behavior: An inventory. Child Development, 36, 417-424.

Scott, W. A., Scott, R., \& McCabe, M. (1991). Family relationships and children's personality: A cross-cultural, cross-source comparison. British Journal of Social Psychology, 30, 1-20.

Sentse, M., Lindenberg, S., Omvlee, A., Ormel, J., \& Veenstra, R. (2010). Rejection and acceptance across contexts: Parent and peer risks and buffers for early adolescent psychopathology. The TRAILS study. Journal of Abnormal Child Psychology, 38, 119-130. doi:10.1007/s10802-009-9351-z.

Silk, J. S., Morris, A. S., Kanaya, T., \& Steinberg, L. (2003). Psychological control and autonomy granting: Opposite ends of a continuum or distinct constructs? Journal of Research on Adolescence, 13, 113-128.

Siqueland, L., Kendall, P. C., \& Steinberg, L. (1996). Anxiety in children: Perceived family environments and observed family interaction. Journal of Clinical Child \& Adolescent Psychology, 25, 225-237.

Van der Bruggen, C. C., Bögels, S. M., \& Zeilst, N. (2010). What influences parental controlling behaviour? The role of parent and child trait anxiety. Cognition \& Emotion, 24, 141-149. doi: 10.1080/02699930802618843.

Van der Bruggen, C. O., Stams, G. J. J. M., \& Bögels, S. M. (2008). Research Review: The relation between child and parent anxiety and parental control: a meta-analytic review. Journal of Child Psychology and Psychiatry, 49, 1257-1269.

Wood, J. J., McLeod, B. D., Sigman, M., Hwang, W. C., \& Chu, B. C. (2003). Parenting and childhood anxiety: Theory, empirical findings, and future directions. Journal of Child Psychology and Psychiatry, 44, 134-151. 